\title{
LHPP, the light-harvesting NADPH:protochlorophyllide (Pchlide) oxidoreductase:Pchlide complex of etiolated plants, is developmentally expressed across the barley leaf gradient ${ }^{\text {th }}$
}

\author{
Christiane Reinbothe ${ }^{\mathrm{a}, 1}$, Stephan Pollmann $^{\mathrm{b}}$, Claire Desvignes ${ }^{\mathrm{c}}$, \\ Martina Weigele ${ }^{c}$, Erwin Beck ${ }^{\mathrm{a}}$, Steffen Reinbothe ${ }^{\mathrm{b}, \mathrm{c}, *}$ \\ a Lehrstuhl für Pflanzenphysiologie, Universität Bayreuth. Universitätsstraße 30, D-95447 Bayreuth, Germany \\ b Ruhr-Universität Bochum, Lehrstuhl für Pflanzenphysiologie, Universitätsstraße 150, Postfach 102148, Gebäude ND3/27, D-44801 Bochum, Germany \\ ' Université Joseph Fourier et Centre National de la Recherche Scientifique (CNRS), UMR 5575, BP53, CERMO, F-38041 Grenoble Cedex 9, France
}

\begin{abstract}
NADPH:protochlorophyllide oxidoreductase is a key enzyme for the light-induced greening of etiolated angiosperm plants. In barley, two POR proteins exist termed PORA and PORB that have previously been proposed to structurally and functionally cooperate in terms of a higher molecular mass light-harvesting complex named LHPP, in the prolamellar body of etioplasts [Nature 397 (1999) 80]. In this study we examined the expression pattern of LHPP during seedling etiolation and de-etiolation under different experimental conditions. Our results show that LHPP is developmentally expressed across the barley leaf gradient. We further provide evidence that LHPP operates both in plants that etiolate completely before being exposed to white light and in plants that etiolate only partially and begin light-harvesting as soon as traces of light become available in the uppermost parts of the soil. As a result of light absorption, in either case LHPP converts Pchlide a to chlorophyllide (Chlide) $a$ and in turn disintegrates. The released Chlide $a$, as well as Chlide $b$ produced upon LHPP's light-dependent dissociation, which leads to the activation of the PORA as a Pchlide $b$-reducing enzyme, then bind to homologs of water-soluble chlorophyll proteins of Brassicaceae. We propose that these proteins transfer Chlide $a$ and Chlide $b$ to the thylakoids, where their esterification with phytol and assembly into the photosynthetic membrane complexes ultimately takes place. Presumably due to the tight coupling of LHPP synthesis and degradation, as well as WSCP formation and photosynthetic membrane assembly, efficient photo-protection is conferred onto the plant.
\end{abstract}

Keywords: Chloroplast development; Chlorophyll biosynthesis; Greening; NADPH:protochlorophyllide oxidorediuctases (POR) A and B; Light-harvesting POR:protochlorophyllide complex (LHPP)

\section{Introduction}

NADPH:protochlorophyllide (Pchlide) oxidoreductase (POR) (EC 1.33.3.1) is a key enzyme for the light-induced greening of etiolated angiosperm plants [1-5]. Both POR

This work was supported by a research project grant (RE1465/1-1, 1-2) from the Deutsche Forschungsgemeinschaft (DFG), Bonn, Germany, to $\mathrm{CR}$

* Corresponding author. Tel.: +33-4765-1-4893;

fax: $+33-4765-1-4336$

E-mail addresses: christiane.reinbothe@uni.bayreuth.de

(C. Reinbothe), steffen.reinbothe@ujf-grenoble.fr (S. Reinbothe).

Co-corresponding author. Fax: +49-921-55-2642. and its pigment substrate Pchlide accumulate to high levels in the leaves of dark-grown plants [6]. Dark-stable Pchlide-NADPH-POR ternary complexes are poised such that absorption of a photon by the pigment itself leads to its immediate reduction (see Ref. [7], for review). As a result, Chlide $a$ is produced which is subsequently esterified and further modified to produce Chls $a$ and $b$ in conjunction with the formation of functional photosynthetic membrane complexes (reviewed in Ref. [8]).

Two different species of Pchlide have been identified by low temperature in situ-fluorescence measurements in etiolated plants: Pchlide-628/632 (the first number indicates the absorption maximum, the second the respective fluorescence 
emission maximum at the chosen excitation wavelength) and Pchlide-650/657 [9-12]. Protochlorophyllide-650/657 is also called photoactive Pchlide, because it can be converted to Chlide-684/690 with a single, $1 \mathrm{~ms}$ flash of white light $[10,13]$. It had thus far been believed that Pchlide-650/657 is constituted by photoactive Pchlide-NADPH-POR ternary complexes accumulating in the prolamellar body of etioplasts. Protochlorophyllide- $628 / 632$, by contrast, is non-photoconvertible and was supposed to be due to the presence of Pchlide aggregates not bound to POR that would transfer their excitation energy onto photoactive Pchlide ([10,13], see also Ref. [7], for review). Energy transfer is known for many decades to take place from photoinactive Pchlide to photoactive Pchlide and from photoinactive Pchlide to Chlide $[10,14-18]$

The existence of Pchlide aggregates has recently been disproven by work of Apel and co-workers. Meskauskiene et al. [19] isolated an Arabidopsis mutant called flu (fluorescent) that is unable to block excess Pchlide accumulation in darkness. In dark-grown angiosperm plants, Pchlide accumulation is normally restricted by a negative feedback loop executed by heme, Pchlide, and the flu protein at the step of 5-aminolevulinic acid formation. The flu protein interacts with glutamyl-tRNA reductase [20] which is one of three enzymes involved in 5-aminolevulinic acid biosynthesis (see Refs. [21,22], for review). In dark-grown flu plants and in light-grown flu plants transferred to darkness, free excited Pchlide molecules interact with $\mathrm{O}_{2}$ and, by triplet-triplet interchange, give rise to highly toxic singlet oxygen [23]. Singlet oxygen in turn triggers membrane lipid peroxidation and has deleterious effects on membrane integrity, plastid ultrastructure, and subsequent plant development. As a result, cell death occurs [23].

A solution for the apparent paradox as to how to explain the presence of photoactive and photoinactive Pchlide species has been provided by previous work. We discovered that in etiolated barley plants two POR proteins exist, termed PORA and PORB [24], that structurally and functionally cooperate in terms of a novel light-harvesting complex termed LHPP [25]. If expressed from corresponding cDNA clones and reconstituted to POR-pigment complexes, using Pchlide $a$ and Pchlide $b$ or their Zn analogs, Zn protopheophorbide ( $\mathrm{ZnPP}) a$ and $\mathrm{ZnPP} b$, respectively, plus NADPH as substrates, PORA and PORB were found to form oligomers in vitro [25-27]. In these oligomeric complexes, 5 PORA-Pchlide $b-\mathrm{NADPH}$ complexes interacted with just 1 PORB-Pchlide a-NADPH ternary complex. The resulting supra-complex additionally bound galacto- and sulpholipids $[25,26]$. We observed that light which was absorbed by PORA-bound Pchlide $b$ was transferred onto PORB-bound Pchlide a $[25,27]$. Similar energy transfer reactions were observed in planta [25]. Moreover, a Pchlide a- and Pchlide $b$-containing PORA/PORB protein complex could be resolved from isolated prolamellar bodies that displayed the same POR, pigment and lipid stoichiometries and interactions as the in vitro-reconstituted complex [26]. Both the in vitro-reconstituted and authentic complex dissociated upon white light illumination [26,37], consistent with previous findings on the light-induced disintegration of the prolamellar body $[10,13]$. Based on these findings we put forth that the reconstituted and authentic complexes are identical [26].

Little information had thus far been available on the regulated expression of LHPP during plant development. In this study, we analyzed the expression pattern and assembly of PORA and PORB, formation of photoactive Pchlide-F650/657, and accumulation of porphyrins and chlorins in barley plants during their etiolation and subsequent de-etiolation.

\section{Materials and methods}

\subsection{Plant growth}

Seeds of barley (Hordeum vulgare cv. Carina) were germinated either in the dark or underneath a $4 \mathrm{~cm}$ layer of vermiculite at $25^{\circ} \mathrm{C}$ in the presence of $5 \mu \mathrm{E} \mathrm{m}^{-2} \mathrm{~s}^{-1}$. Light quality and quantity measurements were made as described in [28].

\subsection{Plastid Isolation}

Seedlings were cut into consecutive $1 \mathrm{~cm}$ sections and plastids isolated by differential centrifugation and Percoll density gradient centrifugation, as described [29].

\subsection{Pigment analyses}

Either extraction with $100 \%(\mathrm{v} / \mathrm{v})$ acetone containing $0.1 \%$ diethyl pyrocarbonate (DEP) or non-aqueous extraction with heptane-carbon tetrachloride $\left[\mathrm{C}_{7} \mathrm{H}_{16} / \mathrm{CCl}_{4} 66: 34\right.$ $(\mathrm{v} / \mathrm{v})$, density $\left.1.28 \mathrm{~g} / \mathrm{cm}^{3}\right]$ were used [26].

Pigment extraction with acetone and hexane used to quantify esterified and non-esterified pigments was carried out according to Helfrich et al. [30], using the following modifications. For in vivo analyses, leaf tissues were extracted with $100 \%(\mathrm{v} / \mathrm{v})$ acetone containing $0.5 \%(\mathrm{v} / \mathrm{v})$ DEP. In turn the assays were centrifuged to sediment protein. After a step of re-extraction of pigments, the withdrawn acetone phases were pooled and supplemented with one third volume of reaction buffer containing $10 \mathrm{mM} \mathrm{MgCl} 2$ and $3 \mathrm{mM} \mathrm{MnCl} 2$ [30]. To the resulting mixture, $50 \mathrm{mg}$ diethylamino-ethyl-cellulose (DEAE2, Whatman) and one half volume of hexane were added. After phase separation, the amount of esterified and non-esterified pigments was determined in the upper and lower solvent phases, respectively [30]. While esterified pigments are retained in the upper, hexane phase, non-esterified pigments partition into the lower, aqueous acetone phase [30]. For in vitro analyses, the same protocol was used except for the fact that each sample was diluted two-fold with doubly concentrated reaction buffer containing $20 \mathrm{mM} \mathrm{MgCl} 2$ and 
$6 \mathrm{mM} \mathrm{MnCl} 2$ before $50 \mathrm{mg}$ diethylamino-ethyl-cellulose (DEAE2, Whatman) and one half volume of hexane were added.

HPLC was performed on either C18 reverse phase silica gel columns (Macherey-Nagel Co., $250 \mathrm{~mm} \times 4.6 \mathrm{~mm}$, Nucleosil ODS $5 \mu \mathrm{m}$ ) [31] or C30 reverse phase columns (YMC Inc., Willmington, NC, USA, $250 \mathrm{~mm} \times 4.6 \mathrm{~mm}$, $5 \mu \mathrm{m})$ [32], using established procedures and a Varian ProStar model 410 apparatus, ProStar model 240 pump and ProStar 330 photodiode array detector. In some experiments, Chlides $a$ and $b$ were separated on RP18 Gromsil columns (Grom, Herrenberg, Germany), using a gradient of $100 \%$ acetone, applied for $3 \mathrm{~min}$, and $60 \%$ acetone $/ 40 \%$ acetic acid-supplemented water, $\mathrm{pH} 6.5$, reached within 20 min [33]. Coupled POR-chlorophyll synthetase reactions were carried out according to Helfrich et al. [30].

Low-temperature luminescence spectroscopy was performed at $77 \mathrm{~K}$ at excitation wavelengths of either 440 or $470 \mathrm{~nm}$ in a spectrometer LS50 (Perkin Elmer Corp., Norwalk, CT) [34].

\subsection{Protein analyses}

Denaturing $10-20 \%(\mathrm{w} / \mathrm{v})$ polyacrylamide gradients containing SDS were prepared according to Laemmli [35], as modified by Scharf and Nover [36]. Non-denaturing separations were as described by Krauspe et al. [37]. Western blotting was carried out according to Towbin et al. [38], exploiting either an anti-rabbit, anti-goat, alkaline phosphatase system or an ECL system (Amersham Pharmacia Biotech, http://www.apbiotech.com), and the antisera indicated in the text. Sequencing of electrophoretically resolved, protease-digested proteins was performed as described by Chang [39] and Chang et al. [40]. WSCP oligomerization was analyzed according to Satoh et al. [41]. Immunoprecipitations were performed according to Wiedmann et al. [42] using an anti-WSCP antiserum of $L$. virginicum.

\section{Results}

\subsection{The experimental design}

Plastid and leaf development are coupled in monocotyledonous plant species such as barley. Leaf development is determined by basipetal cell growth in the lower, youngest parts of the leaf (the leaf meristem) and maturation of tissues in the older parts. Plastid development follows a similar course: proplastids present in the leaf base continuously differentiate into mature forms. Depending on whether leaf development proceeds in darkness or light (processes termed skotomorphogenesis and photomorphogenesis, respectively, Ref. [43]) etioplasts and chloroplasts are produced [44]. In a typical germinating barley seedling a developmental gradient thus is established, comprising proplastids in the leaf base, developing etioplasts or chloroplasts in the middle, and mature plastids in the leaf tip [45].
Taking into account this pattern, 5-day-old etiolated barley seedlings were cut under a dim green light into consecutive $1 \mathrm{~cm}$ segments designated I-V in Fig. 1A. Subsequently, each of the different leaf samples was divided laterally into two halves. One half was used for in situ-fluorescence spectroscopy, whereas the other half was immediately used for protein extraction and analysis of POR-related proteins by SDS-PAGE.

(A)

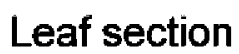

(B)
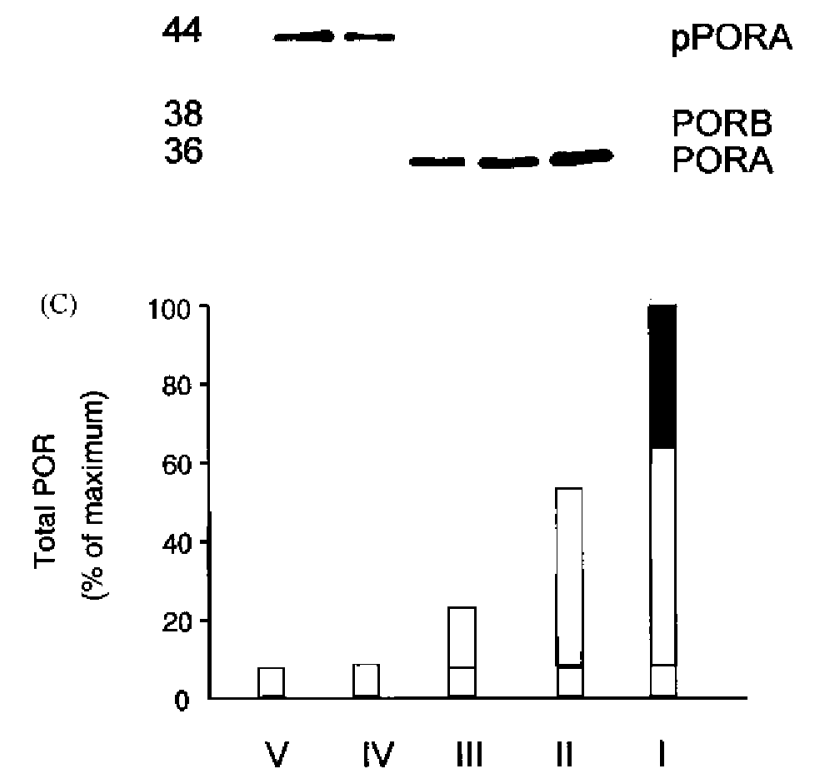

(D) MALQLLPSTLSVPKKGSSWSAVAVKOTAAFLGVSSKAKKSIAVRTQV

pPORA

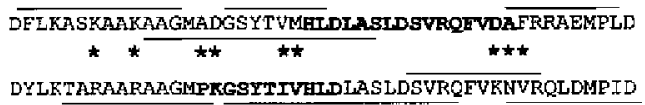

PORB PORA

Fig. 1. Developmental expression of POR in a typical etiolated barley seedling. (A) Depiction of the experimental design. (B) Western blot analysis of POR-related proteins in the various leaf sectors indicated in (A). (C) Quantification of PORA (grey columns) and PORB protein (white columns) levels relative to the total amount of POR in the indicated leaf segments. (D) Partial amino acid sequences of the pPORA, PORA and PORB. In addition to part of pPORA's transit peptide, two regions in the mature PORA and PORB are shown in which the obtained peptide sequences are most divergent. Dots highlight fingerprint amino acids. Staphylococcus aureus V8 protease-derived and endoproteinase Lys C-derived amino acid sequences are overlined and underlined, respectively. Amino acid sequences obtained after cyanogen bromide cleavage are in bold face. 


\subsection{PORA and PORB are developmentally expressed across the barley leaf gradient}

Total protein was recovered from sonicated leaf material by precipitation with trichloroacetic acid, washed with ethanol and ether, and electrophoresed in denaturing $10-20 \%$ polyacrylamide gradients containing SDS. Nitrocellulose filters containing protein from the above defined leaf fractions (see Fig. 1A) were then probed with a POR-specific antiserum (see Section 2).

Fig. 1B demonstrates that three POR-related proteins could be detected, displaying molecular masses of 44,38 and $36 \mathrm{kDa}$, respectively. According to our previous studies $[24,46]$, these POR proteins were likely to represent the cytosolic precursor of the PORA, pPORA $(44 \mathrm{kDa})$, the mature PORB $(38 \mathrm{kDa})$ and the mature PORA $(36 \mathrm{kDa})$. Large-scale isolation from multiple gels of the 44,38 and $36 \mathrm{kDa}$ bands plus subsequent sequencing of proteolytic fragments generated with cyanogen bromide or different proteases confirmed that the $44 \mathrm{kDa}$ protein indeed represents the pPORA and its mature, $36 \mathrm{kDa}$ form, whereas the partial sequence information for the $38 \mathrm{kDa}$ band demonstrated that it is identical with PORB (Fig. 1D).

The total amount of POR was lowest in the youngest parts of the leaf and increased with leaf age, but the abundances of the PORA and PORB changed differentially in the various leaf sections (Fig. 1B and C). PORA seemed confined to the uppermost, oldest parts of the etiolated leaf. By contrast, PORB accumulated to similar levels throughout the entire leaf gradient (Fig. 1B and C). Remarkably, the $44 \mathrm{kDa}$ pPORA was most abundant in the youngest parts of the leaf, containing proplastids, while its level declined in the older parts, such that the protein was barely detectable in the leaf tip (Fig. 1B).

\subsection{Coordinated expression of both PORA and PORB correlates with the appearance of Pchlide F657 and higher molecular mass complexes indicative of LHPP}

Low temperature $(77 \mathrm{~K})$ in situ-fluorescence spectroscopy was performed at an excitation wavelength of $440 \mathrm{~nm}$ [34] of replicate samples corresponding to those used for protein extraction. When the spectra were compared, Pchlide-628/632 and Pchlide-650/657 were readily detectable in the leaf tip (sector I) and middle leaf sector (sector III) (Fig. 2A, solid and dotted lines, respectively). In the leaf base, only Pchlide-628/632 appeared (Fig. 2A, dashed line). At an excitation wavelength of $470 \mathrm{~nm}$, in leaf sectors I and III only Pchlide-650/657 was observed (Fig. 2B, solid and dotted lines, respectively). In the leaf base, no fluorescence was detectable (Fig. 2B, dashed line). After illumination with a single, $1 \mathrm{~ms}$ flash of white light, Pchlide-650/657 was converted to Chlide-684/690 (Fig. 2C and D). By contrast, Pchlide-F628/632 remained unchanged (Fig. 2C and D).
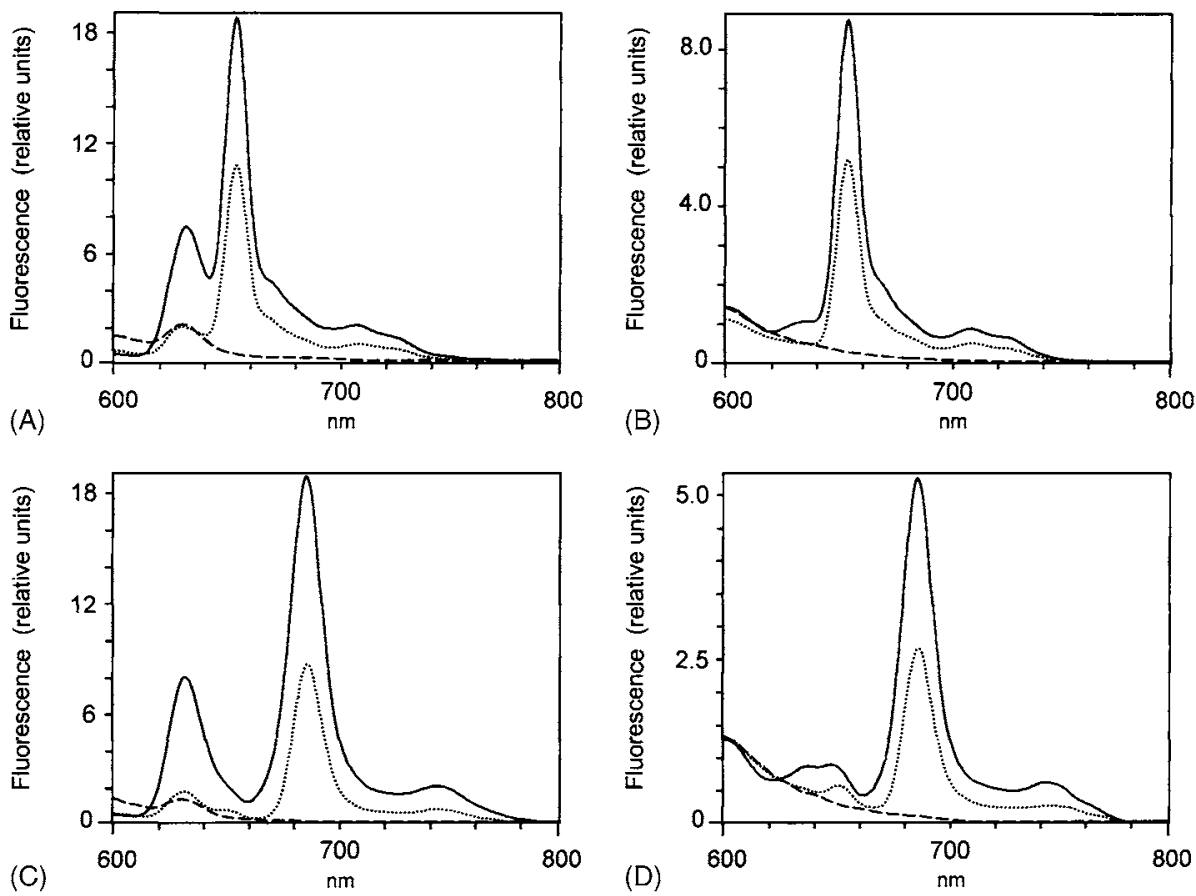

Fig. 2. In situ-fluorescence analysis at $77 \mathrm{~K}$ of pigments in a typical etiolated barley leaf before and after exposure to a single, $1 \mathrm{~ms}$ flash of white light. Leaf material was prepared as described in Fig. 1A and probed by low temperature in situ-fluorescence spectroscopy at $77 \mathrm{~K}$ (A and B). Then the samples were warmed to about $\sim 25^{\circ} \mathrm{C}$ and subjected to a $1 \mathrm{~ms}$ flash of white light before being measured a second time at $77 \mathrm{~K}$ (C and D). (A) Fluorescence emission analysis at an excitation wavelength of $440 \mathrm{~nm}$ of etiolated leaf samples. (B) as (A), but at an excitation wavelength of $470 \mathrm{~nm}$. (C) Fluorescence emission analysis at an excitation wavelength of $440 \mathrm{~nm}$ of flashed leaf samples. (D) as (C), but at an excitation wavelength of $470 \mathrm{~nm}$. Note the almost quantitative conversion of Pchlide-650/657 to Chlide F690 in the leaf tip (sector I, solid line) and the middle leaf sector (sector III, dotted line), but the lack of Chlide-684/690 and other long-wavelength pigments in the leaf base (sector $\mathrm{V}$, dashed line). 

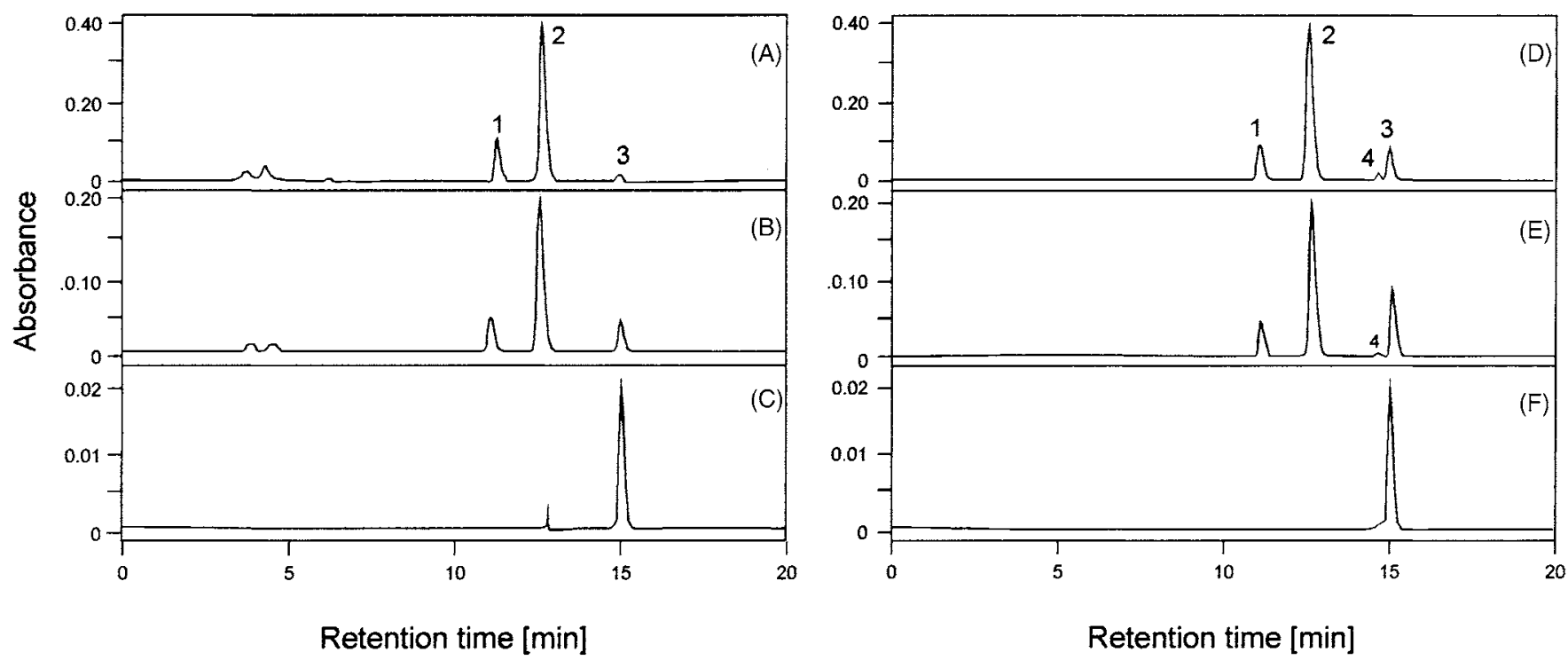

Fig. 3. HPLC analysis of pigments extracted from etiolated and flashed barley plants. Plants were prepared as described in Fig. 1A and cut into two halves of which one was cooled to $-196^{\circ} \mathrm{C}$ and subjected to pigment extraction. The other halves were exposed to a single $1 \mathrm{~ms}$ flash of white light (see Fig. 2) before being frozen, extracted and analyzed further by HPLC on a C18 RP column. Pigments were detected at $455 \mathrm{~nm}$. (A) Chromatogram of pigments extracted from leaf sector I. (B) Chromatogram of pigments extracted from leaf sector III. (C) Chromatogram of pigments extracted from leaf sector V. (D) as (A), but showing pigments from leaf samples that had been flashed prior to pigment extraction and analysis. (E) as (B), but showing pigments from flashed leaf material. (F) as (C), but showing pigments from flashed samples. Main peaks denoted 1, 2, 3 and 4 correspond to 7-OH-Pchlide a (peak 1), Pchlide $b$ (peak 2), Pchlide a (peak 3), and Chlide a (peak 4). Note that part of the Pchlide $b$ is converted to Pchlide a by virtue of 7 -formyl reductase activity present in barley etioplasts.

HPLC analyses were performed to identify and quantify pigments present in the different leaf samples before and after flash light-illumination. As shown previously, Pchlide $a$ and Pchlide $b$ as well as the presumed intermediate in Pchlide $b$ to Pchlide a conversion, 7-OH-Pchlide $a$, can be resolved on C18 RP material [27,31]. Also the product of light-dependent pigment conversion, Chlide $a$, is separable on this column material [27].

Fig. 3A-C shows chromatograms of pigments extracted with $100 \%$ acetone containing $0.1 \%(\mathrm{v} / \mathrm{v})$ diethyl pyrocarbonate from lyophilized leaf samples corresponding to those designated I, III and V in Fig. 1 A. At an absorption wavelength of $455 \mathrm{~nm}$, which corresponds to the Soret band of Pchlide $b$ [31], three main pigment species were detectable, eluting at $11 \mathrm{~min}$ (peak 1), $12.5 \mathrm{~min}$ (peak 2) and $15 \mathrm{~min}$ (peak 3 ), respectively. These peaks had previously been identified as 7-OH-Pchlide $a$ (peak 1), Pchlide $b$ (peak 2) and Pchlide a (peak 3) [27].

To provide further evidence for the identity of these compounds, the following experiment was performed. Pigments were recovered from the various HPLC fractions, concentrated, and used as substrates for the POR reaction in vitro. PORA and PORB polypeptides were expressed from corresponding cDNAs, purified and reconstituted into POR-pigment-NADPH complexes. PORA was mixed with pigments recovered from peak 2 eluting at $12.5 \mathrm{~min}$, whereas PORB was incubated with pigments recovered from peak 3 eluting at $15 \mathrm{~min}$ during HPLC. All incubations were performed in the presence of NADPH. Reconstituted
POR-pigment-NADPH complexes were separated from the bulk of non-bound pigment by gel filtration on Sephadex G15 [29]. POR-pigment-NADPH complexes eluting with the flow-through in turn were exposed to a saturating flash of white light to induce enzymatic Chlide formation. After extraction with acetone, the released Chlide was used as substrate for the chlorophyll synthetase reaction [30]. Esterified pigments (i.e., $\mathrm{Chl} a$ and $\mathrm{Chl} b$ ) were separated from non-esterified pigments by acetone/hexane extraction [30] and analyzed by HPLC. Pigments were identified by their characteristic absorbance spectra and mass spectroscopy.

Fig. 4 shows absorption spectra of pigments produced by the coupled POR-chlorophyll synthetase reaction. It turned out that the absorption spectra of pigments produced with PORB were identical to those of Chl $a$, whereas those obtained with PORA were identical to those of $\mathrm{Chl} b$. Mass spectrometry confirmed the identity of these compounds (Table 1) and thus ultimately proved that the pigments eluting at 12.5 and $15 \mathrm{~min}$ on the C18 material represent Pchlide $b$ and Pchlide $a$, respectively. For the pigment eluting at $11 \mathrm{~min}$, both with PORA and PORB 7-OH-Chl a was produced by the coupled POR-chlorophyll synthetase reaction. PORA and PORB also converted Pchlide $a$ and Pchlide $b$ present in the different HPLC fraction into their respective products, but their binding affinities for these compounds were 10-fold lower in either case than those measured for their natural substrates (data not shown).

Quantification of 7-OH-Pchlide $a$, Pchlide $b$ and Pchlide $a$ is summarized in Table 2. It revealed that the total amount 

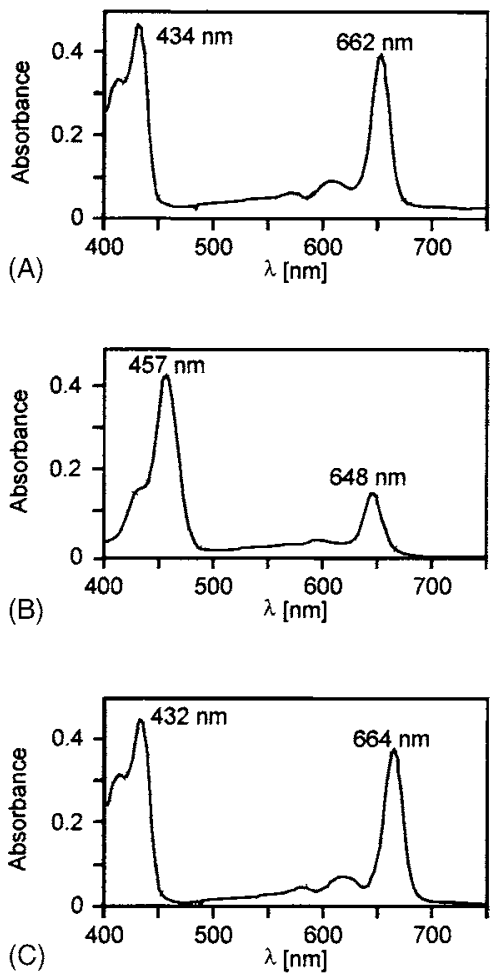

Fig. 4. Absorption spectra of $\mathrm{Chl} a, \mathrm{Chl} b$ and 7-OH-Chl a, produced by virtue of coupled POR-chlorophyll synthetase reaction. Pigment extraction and separation by HPLC were as described in Fig. 3. Conversion of pigments to their reduced forms and subsequent esterification were performed by coupled POR-chlorophyll synthetase reactions. Identification and quantification of esterified and non-esterified pigments were achieved after hexane/acetone extraction by absorbance measurements. (A) Absorption spectrum of 7-OH-Chl a. (B) Absorption spectrum of Chl b. (C) Absorption spectrum of Chl a.

of Pchlide was highest in the leaf tip and gradually declined in the younger parts of the plant. In the leaf base, low but statistically significant levels of Pchlide a were detected, whereas the leaf tip and middle leaf sector contained an excess of Pchlide $b$ relative to Pchlide a (Table 2).

Table 1

Identification of pigments by liquid secondary-ion mass spectrometry

\begin{tabular}{llll}
\hline Pigment & $m / 2$ & & \\
\cline { 2 - 4 } & Natural compound & Standard & Reference \\
\hline 7-OH-Chl a & 909.3 & 909.5 & $\mathrm{~A}$ \\
Chl $b$ & 907.2 & 907.25 & $\mathrm{~B}$ \\
Chl $a$ & 893.5 & 893.53 & $\mathrm{~B}$ \\
\hline
\end{tabular}

Leaf samples were prepared as described in Fig. $1 \mathrm{~A}$ and pigments extracted with acetone. After HPLC on C18 RP material, 7-OH-Pchlide a, Pchlide $b$ and Pchlide $a$ were converted to 7-OH-Chl $a, \mathrm{Chl} b$ and $\mathrm{Chl} a$ by coupled POR-chlorophyll synthetase reactions. The esterified pigments were then subjected to mass spectroscopy. $m / z$-values were obtained from mass spectra of the molecular-ion regions of chemically pure compounds. References refer to either synthetic (7-OH-Chl a) or commercially available (Chl $a$ and $\mathrm{Chl} b$ ) standards and are the followings: (A) [78]; (B) http://www.sigma-aldrich.com.
Table 2

Quantification of pigments in etiolated barley leaves before and after a $1 \mathrm{~ms}$ flash of white light

\begin{tabular}{lrrrrr}
\hline Pigment & I & II & III & IV & V \\
\hline Darkness & & & & & \\
Pchlide $a$ & 12 & 10 & 11 & 8 & 8 \\
Pchlide $b$ & 88 & 45 & 30 & - & - \\
Chlide $a$ & - & - & - & - & - \\
Chlide $b$ & - & - & - & - & - \\
After flash light & & & & & \\
Pchlide $a$ & 2 & 5 & 8 & 9 & 6 \\
Pchlide $b$ & 86 & 40 & 25 & - & - \\
Chlide $a$ & 12 & 10 & 8 & - & - \\
Chlide $b$ & - & - & - & - & -
\end{tabular}

Non-aqueous pigment extraction and HPLC on C18 RP material were performed as described (see Fig. 1). Quantification of porphyrins (Pchlide $a$ and Pchlide $b$ ) was made by absorbance measurements at $455 \mathrm{~nm}$, using chemically synthesized Pchlides $a$ and $b$ as standards. Chlorins were separated on C30 RP material [32] and quantified as described by Scheumann et al. [31] and Oster et al. [33]. Dashes indicate not-detectable pigment levels. Percentages refer to total pigment levels in leaf sector I, set as 100 . Note that part of the Pchlide $b$ present in leaf sectors I-III is converted to Pchlide $a$ by virtue of 7 -formyl reductase activated upon flash light-illumination.

In addition to the HPLC analyses, non-denaturing PAGE was performed which has previously allowed the identification of higher molecular mass POR-pigment complexes from lyophilized prolamellar bodies [26]. Fig. 5A (darkness) shows a non-denaturing PAGE of POR-pigment complexes recovered from the same type of leaf samples as those used before for pigment extraction and HPLC. Due to the red light-induced auto-fluorescence of Pchlide-650/657, higher molecular mass complexes indicative of LHPP could be detected. Immunoprecipitations using the anti-POR antiserum described previously revealed that these complexes contained POR (Fig. 5B). Upon flash light-illumination, they rapidly dissociated into the PORA and PORB (Fig. 5A). Protein identification and quantification made as described [26] showed that the non-dissociated complex present in the non-flashed leaf tips contained ca. 8.5-fold higher levels of PORA than PORB and that the amount of PORA relative to PORB thus exceeded previously reported levels [25,27]. However, in leaf sector II only a five-fold higher level of PORA than PORB was found (Fig. 5A, flash light), consistent with previous results in which the leaf tip had been disregarded for analysis. Similar $\sim 8.5: 1$ and $\sim 5: 1$ stoichiometries as those measured for PORA and PORB, respectively, were determined for Pchlide $b$ and Pchlide $a$. These results were in agreement with the results obtained for the total leaf samples (see Table 2). Leaf sector V did not seem to contain detectable PORA protein levels and only traces of Pchlide $b$ were found, which confirmed the results shown in Figs. 1 and 3 , respectively.

In flash light-illuminated samples, which no longer contained higher molecular mass complexes indicative of LHPP (Fig. 5A, Flash light), only Chlide a was produced (Table 2). This Chlide a co-migrated with the 


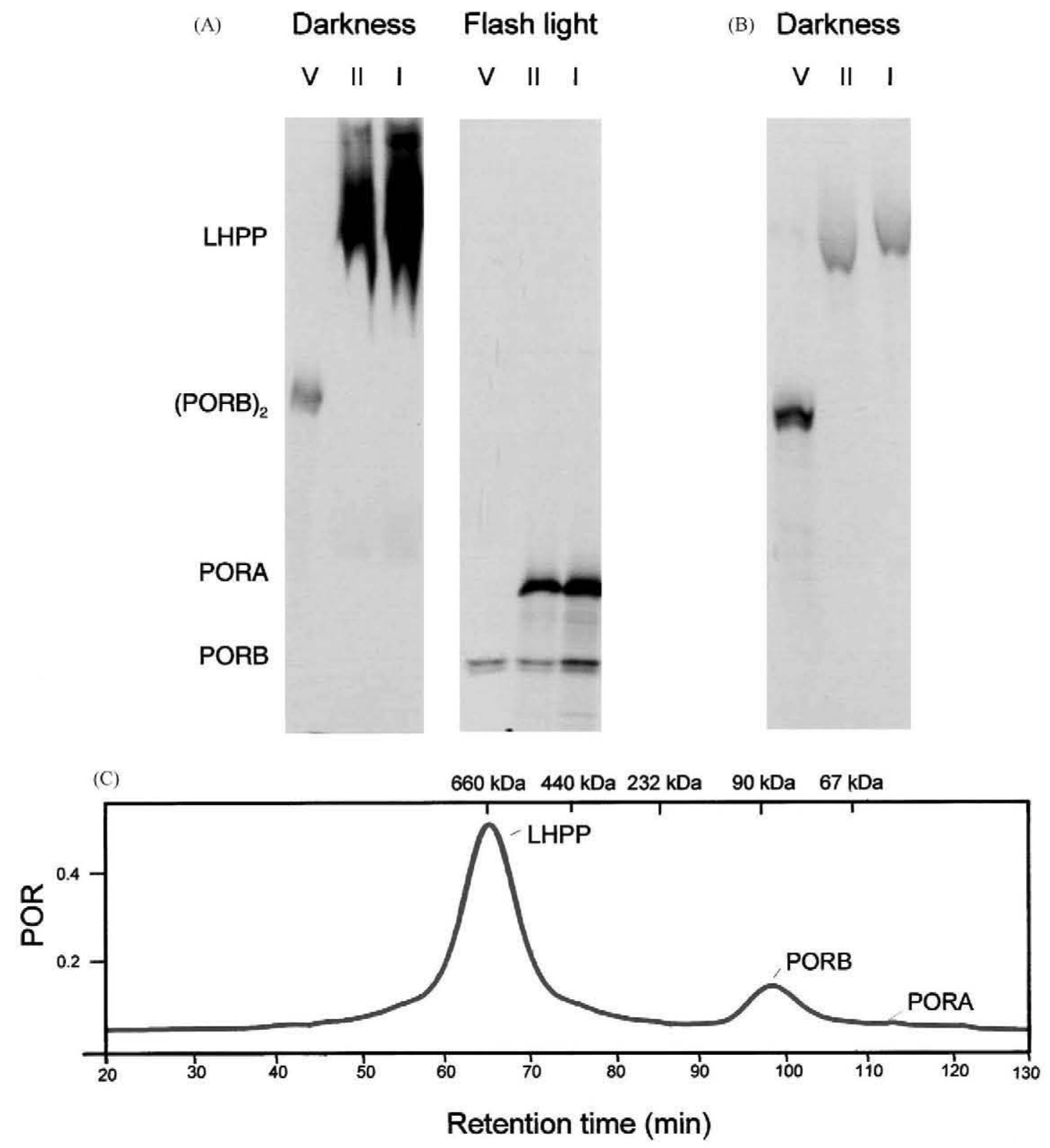

Fig. 5. Non-denaturing, analytical PAGE of POR pigment complexes recovered from lyophilized leaf tissues. Higher molecular mass POR pigment complexes were extracted from leaf sections corresponding to those in Fig. 1, and aliquots kept in darkness or exposed to a $1 \mathrm{~ms}$ flash of white light. After solubilization with $0.2 \%$ Triton X100, a fraction of POR-pigment complexes recovered from the dark samples was subjected to immunoprecipitation with POR antiserum. (A) Detection of POR-pigment complexes in non-flashed (darkness) and flashed (flash light) plastid samples by their pigment auto-fluorescence at an excitation wavelength at $455 \mathrm{~nm}$. (B) Immunoprecipitation of POR-pigment complexes from an aliquot of the extracts of non-flashed samples shown in (A). (C) Size fractionation of POR pigment complexes recovered from leaf sector II of non-flashed plants. Migration of size markers is indicated on top.

PORB protein band (data not shown, but see [26]). Pchlide $b$ present in similar amounts both before and after flash light-illumination (Table 2) co-fractionated with the PORA protein band (data not shown, but see [26]). These results confirmed that only Pchlide $a$ had been photoreduced.

Fractionation on Superose 6 was used to determine the size of the higher molecular mass complex recovered from leaf sector II of the non-flashed sample. Fig. 5C shows that the resolved complex had an apparent size of ca. $660 \mathrm{kDa}$.
In addition, PORB dimers and trace amounts of PORA monomers were detected (Fig. 5C).

\subsection{Greening under natural conditions}

The phenomenon of etiolation has sometimes been disregarded as a natural aspect of seedling development, because most plants green without a prolonged period of dark growth. However, plants which display a hypogeic type of germination partially etiolate while reaching the uppermost parts of 

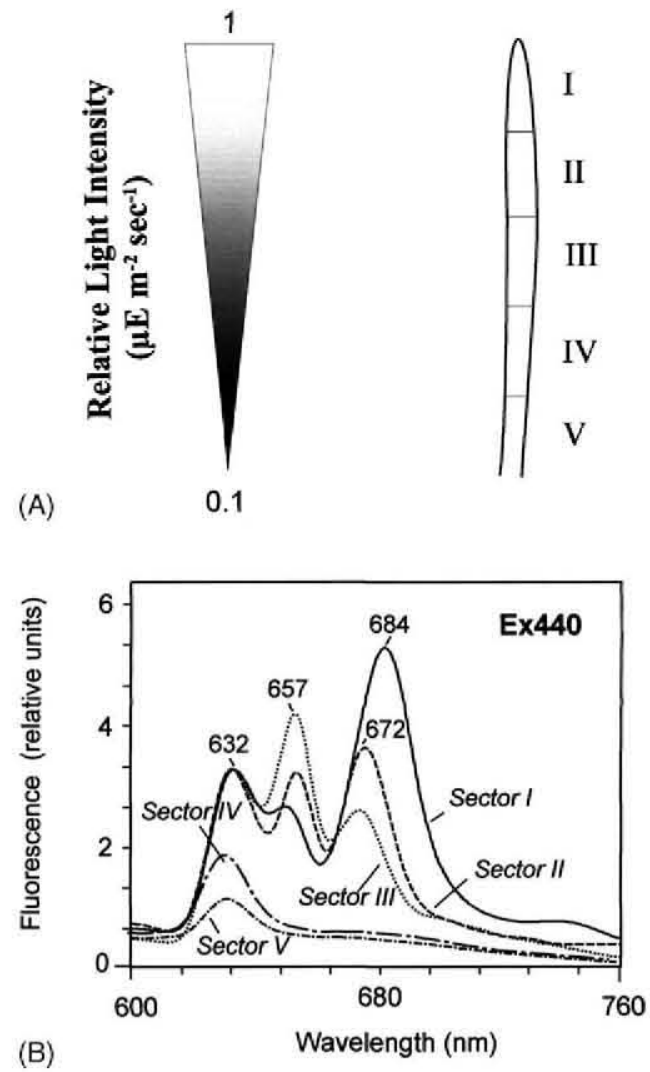

Fig. 6. In situ-fluorescence analysis of pigments during natural greening. Leaf samples were cut into consecutive sectors designated I-V and subjected to low temperature in situ-fluorescence spectroscopy at $77 \mathrm{~K}$. (A) Depiction of the experimental design and established exponential light gradient between $\sim 0.01$ and $\sim 1 \mu \mathrm{Em}^{-2} \mathrm{~s}^{-1}$. (B) Fluorescence emission spectra of pigments at an excitation wavelength of $440 \mathrm{~nm}$ (Exc 440) of pigments found in the leaf tip (sector I, solid line), leaf sector II (dashed line), leaf sector III (dotted line), leaf sector IV (long hatches), as well as the leaf base (sector V, short hatches).

the soil. Interestingly, in this region some light-harvesting already takes place: light passing through or being scattered by particles of the soil is harnessed and in turn drives Chl biosynthesis (see Fig. 6A for a schematic presentation, and Smith, 1982, for references). Whether this "natural greening" would involve LHPP was thus far unknown and motivated us to perform the following experiments.

Barley seeds were placed onto a $1 \mathrm{~cm}$ layer of moist vermiculite and covered with another, $4 \mathrm{~cm}$ layer of this soil substitute. Then, the pots were exposed to dim white light of $5 \mu \mathrm{E} \mathrm{m}^{-2} \mathrm{~s}^{-1}$, giving rise to an exponential light gradient between $\sim 0.01 \mu \mathrm{E} \mathrm{m}^{-2} \mathrm{~s}^{-1}$ (sector $\mathrm{V}$ ) and $\sim 1 \mu \mathrm{E} \mathrm{m}^{-2} \mathrm{~s}^{-1}$ (sector I). After 5 days, the plants were harvested and leaves cut into consecutive segments essentially as described before. In turn, low temperature pigment measurements were performed at $77 \mathrm{~K}$, at an excitation wavelength of $440 \mathrm{~nm}$.

Fig. 6B shows respective spectra which revealed that in the leaf base (sector V) and the adjacent leaf sector IV only one pigment species could be seen: Pchlide-628/632. In all subsequent sectors, this Pchlide- $628 / 632$ as well as
Pchlide-650/657 were detectable. The intensity of the latter pigment species was highest in sector III (Fig. 6B, dotted line), but lower in sector II (hatched line) and sector I (solid line).

Apparently, its emission maximum was shifted toward a slightly shorter wavelength in sector I. In addition, a novel peak appeared which displayed a fluorescence maximum at $684 \mathrm{~nm}$. In sectors III and II, by contrast, a pigment fluorescing at $672 \mathrm{~nm}$ was found.

\subsection{Light-induced disintegration of LHPP during natural greening}

An explanation for these findings could be that the formation of LHPP correlates with the establishment of Pchlide-650/657 and that upon light absorption LHPP would dissociate. As shown previously, the prolamellar body which contains LHPP rapidly disintegrates upon illumination $[10,47-49]$. We hypothesized that if LHPP's light-dependent dissociation was to occur, PORA may be activated and could convert its bound Pchlide $b$ to Chlide $b$. As a result, PORA would be destabilized and turned over. As shown previously, PORA complexed with Chlide is rapidly degraded by a light-, ATP- and metal ion-dependent stromal protease $[50,51]$.

We hypothesized that Chlide $b$ produced during the degradation of the PORA could bind to other proteins. A water-soluble chlorophyll protein (WSCP) was recently discovered for barley etiochloroplasts [52] that displays similarity to WSCPs of Brassicaceae [41]. Interestingly, in cauliflower WSCPs bind both $\mathrm{Chl} a$ and $\mathrm{Chl} b$ but exhibited pigment fluorescence at $680 \mathrm{~nm}$ only when present in a homo-oligomeric state [41]. We assumed that if similar homo-oligomeric WSCP complexes would be present in barley etiochloroplasts, their accumulation could explain the appearance of the fluorescence peak at $\sim 684 \mathrm{~nm}$ (Fig. 6B). Alternatively, this fluorescence peak could be due to formation of either free Chlide a or Chl a-complexed type II reaction centers (RCII) [34].

Protein analyses and pigment measurements were performed to gain insight into these different possibilities. When we probed western blots with the POR antiserum, both PORA and PORB were detectable in sectors II and III, but only a small amount of PORA was present in the leaf tip (sector I) (Fig. 7A). In leaf sector IV, only PORB was found. The leaf base did not contain either PORA or PORB, but expressed significant levels of the $44 \mathrm{kDa}$ pPORA (Fig. 7A). The level of this pPORA declined in leaf sectors IV and III, and it was below the limit of detection in sectors II and I.

Pigment measurements were made by HPLC in order to quantify Pchlide $a$ and Pchlide $b$ as well as Chlide $a$ and Chlide $b$ levels in the various leaf tissues. In addition to the described C18 RP material (see above), separations were performed on $\mathrm{C} 30$ columns that have previously been shown to permit simultaneous separation of Chlide $a$ and Chlide $b$ and their esterified products, i.e., $\mathrm{Chl} a$ and $\mathrm{Chl} b$, re- 
(A)

\section{$\mathrm{kDa}$ \\ V IV III II I}
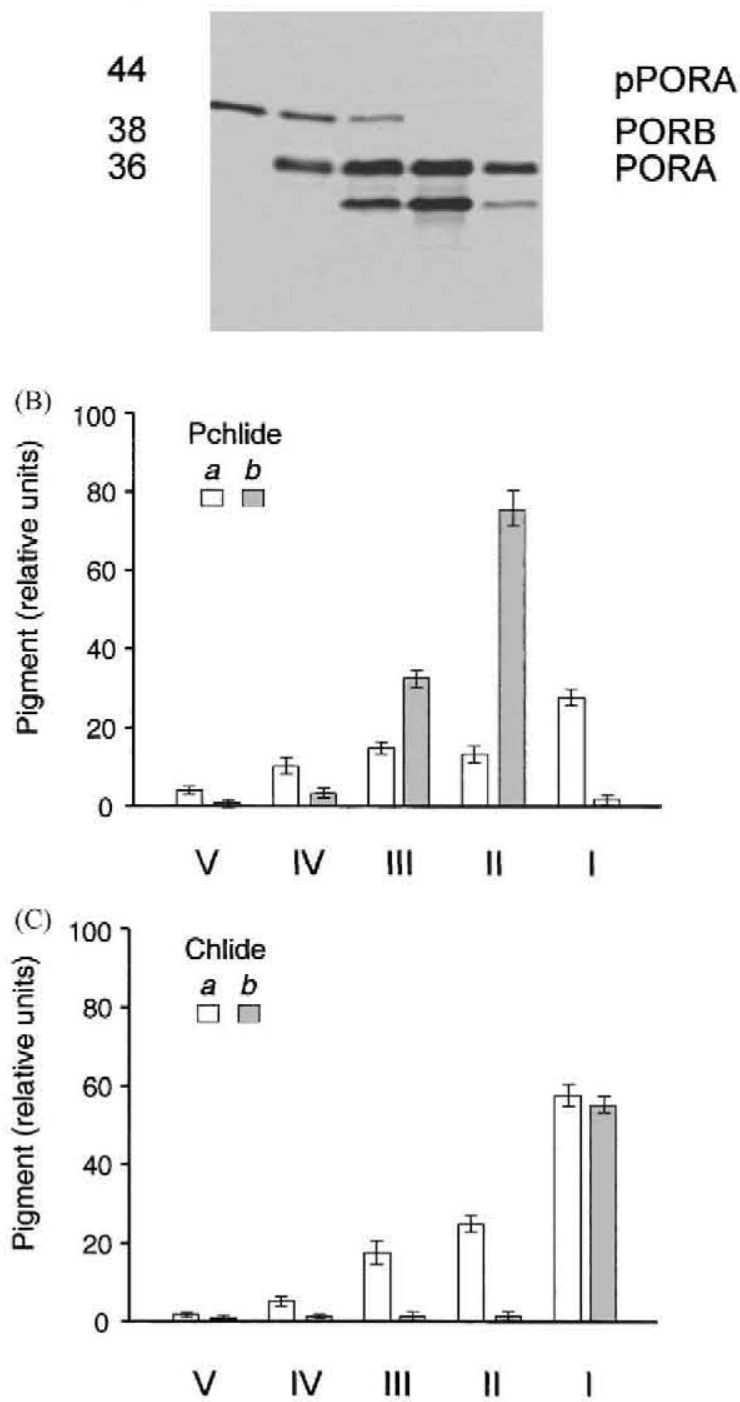

Fig. 7. POR expression in relation to Pchlide and Chlide levels during natural greening. Plants were grown as described in Fig. 6 and proteins and pigments extracted and quantified. (A) Western blot of POR-related proteins. (B) Quantification of Pchlide $b$ (grey columns) and Pchlide $a$ (white columns) levels relative to the total amount of Pchlide in the indicated leaf segments. (C) Quantification of Chlide $a$ and Chlide $b$ levels relative to the total amount of Chlide in the indicated leaf samples. Bars indicate standard deviations determined from five independent experiments.

spectively [26]. Fig. 7B and C summarizes the results. They demonstrate that approximately equal amounts of Chlide $a$ and Chlide $b$ were present in the leaf tip. This part of the plant also contained Pchlide $a$, but only small amounts of Pchlide $b$ (Fig. 7B). This latter pigment was highly abundant in sector II (Fig. 7B). In this region of the seedling, Pchlide $b$ levels exceeded those of Pchlide $a$ by a factor of $\sim 8.5$, which seemed largely consistent with the different PORA and PORB protein stoichiometries on the western blots (Fig. 7A). In leaf sector III, Pchlide $b$ levels were found

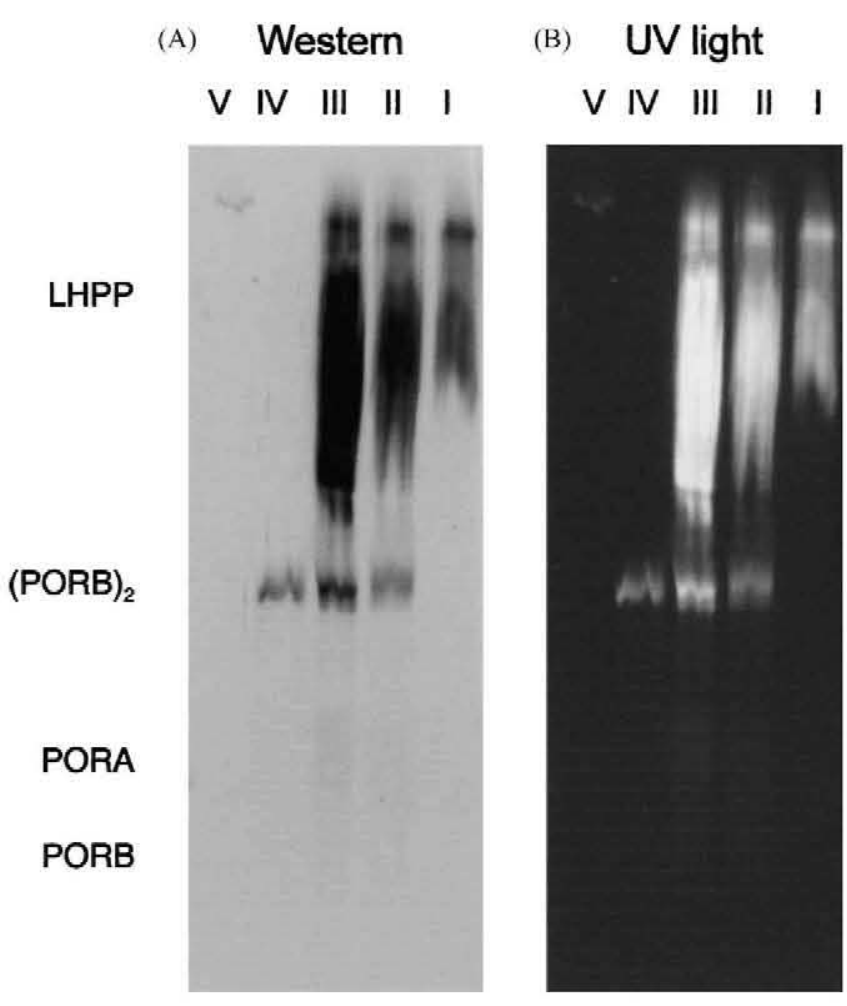

Fig. 8. Non-denaturing, analytical PAGE of POR-pigment complexes during natural greening. Proteins were extracted as described and separated by non-denaturing, analytical PAGE (see Fig. 5). POR pigment complexes were visualized under UV-light and subsequently blotted onto a nitrocellulose membrane. (A) UV light-induced auto-fluorescence of the resolved POR-pigment complexes. (B) Immuno-detection of POR-pigment complexes in the various leaf tissues.

to be ca. five-fold higher than those of Pchlide a (Fig. 6B), but only traces of Chlide $b$ accumulated (Fig. 7C).

Non-denaturing PAGE was used to study the association of the PORA and PORB in terms of larger complexes in the various leaf sectors. Fig. 8 shows that higher molecular mass complexes indicative of LHPP were found in leaf sectors I, II and III, but apparently not in sectors IV and V. The level of these LHPP complexes was highest in sector III and decreased in sectors II and I (Fig. 8), apparently correlating with a drop in the level of Pchlide-650/657 and an increase in the levels of pigments fluorescing at 672 and $684 \mathrm{~nm}$ (see Fig. 6B). Western blot analyses (Fig. 8B) showed that, except for PORB dimers, no other POR protein bands were detectable. On the basis of this result we concluded that the PORA and PORB were most likely present in a free, non-pigment-complexed that was degraded.

\subsection{Pigment binding to WSCPS and photosystem II core and antenna polypeptides}

Collectively the results shown in Figs. 6-8 strengthened the hypothesis that LHPP would progressively disintegrate in leaf sectors III, II and I, and that Chlide $a$ and Chlide $b$ released from the PORA and PORB upon their dissociation and subsequent degradation would bind to WSCPs. The 


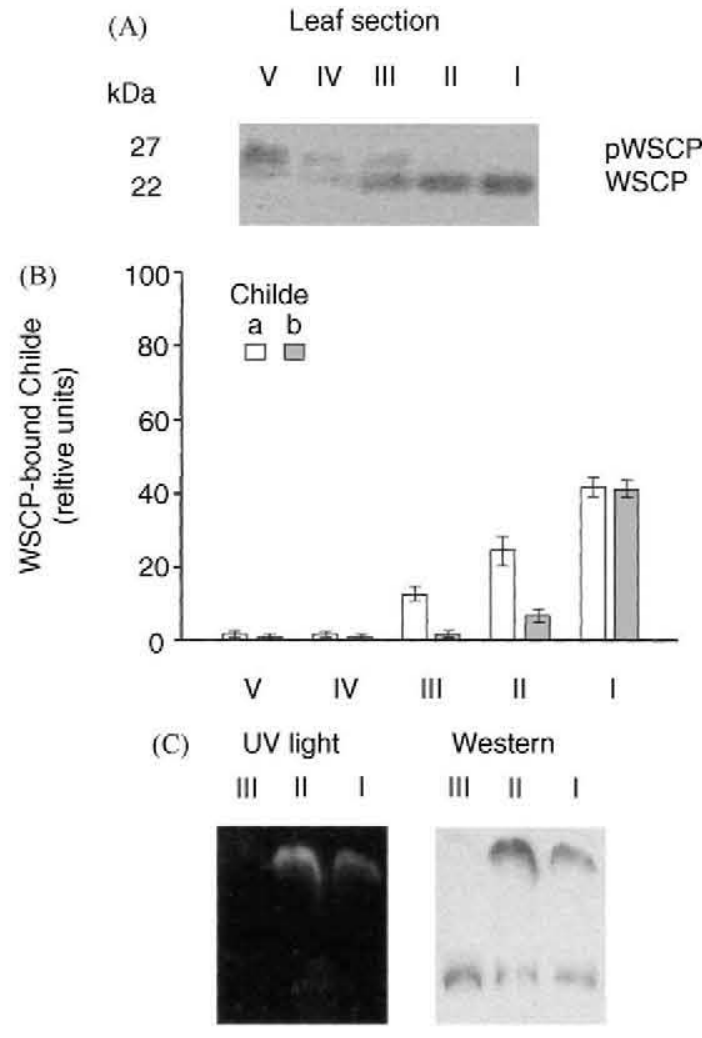

Fig. 9. Expression of WSCP-related proteins in relation to Chlide a and Chlide $b$ levels during natural greening. Plants were grown as described in Fig. 6 and proteins and pigments extracted and quantified. In parallel, stromal proteins were prepared from isolated chloroplasts and subjected to immuno-precipitation using anti-WSCP antiserum of $L$. virginicum. After a brief $\mathrm{pH}$ shift in order to release the bound $\mathrm{IgG}$, aliquots of the resulting immunocomplexes were extracted with acetone or administered to non-denaturing PAGE. (A) Western blot of WSCP-related proteins in barley. (B) Quantification of WSCP-bound Chlide $a$ and Chlide $b$ after their extraction with acetone. Bars indicate standard deviations determined from five independent experiments. (C) Detection of WSCP oligomers by non-denaturing PAGE and subsequent inspection of the gels under UV light or by western blotting.

barley WSCP is a nucleus-encoded plastid protein which is synthesized as a $27 \mathrm{kDa}$ precursor. Import into the plastid occurs under conditions when Chlide is produced, and the $27 \mathrm{kDa}$ precursor is processed to mature size of $22 \mathrm{kDa}$ [52].

Immunological studies were performed with a heterologous antiserum against Lepidium virginicum WSCP to which the barley homolog is most related [52]. Fig. 9A demonstrates that both the $27 \mathrm{kDa}$ precursor and its mature, $22 \mathrm{kDa}$ WSCP could be detected on Western blots of proteins from leaf sections as used for protein and pigment extraction. While highest $27 \mathrm{kDa}$ pWSCP levels were present in leaf sector $\mathrm{V}$, maximal amounts of the mature $22 \mathrm{kDa}$ WSCP were found in leaf sector I.

To identify, quantify and study the functional state of WSCP-bound pigments, plastids were isolated from the various leaf sectors described in Fig. 6A, lysed, and stromal proteins subjected to immuno-precipitation with the anti-Lepidium-WSCP antiserum described before. The re- sulting immunocomplexes in turn were analyzed further in two different ways. One part of the immunocomplexes was directly extracted with $100 \%$ acetone containing $0.1 \%$ diethyl pyrocarbonate, and pigments resolved by HPLC and quantified by absorbance and fluorescence measurements as specified above. The other part was analyzed by non-denaturing PAGE.

Fig. 9B demonstrates that both Chlide $a$ and Chlide $b$ could be extracted with acetone from the stromal immunoprecipitates of sectors I and II. In the leaf tip, approximately equimolar levels of Chlide $a$ and Chlide $b$ were detected (Fig. 9B). In leaf sector II, Chlide a levels exceeded those of Chlide $b$ (Fig. 9B). The relative ratio of Chlide $a$ to Chlide $b$ was even further pronounced in favor of Chlide $a$ in leaf sector III (Fig. 9B).

The second half of the recovered immunocomplexes was subjected to a brief $\mathrm{pH}$ shift to deplete them of the bound IgG and subsequently electrophoresed under non-denaturing conditions (see Section 2). WSCP oligomers presumably present in the different leaf sectors were detected under UV light by their pigment auto-fluorescence (Fig. 9C, left panel). Then, the gel was blotted onto nitrocellulose and the filter probed with anti-WSCP antiserum (Fig. 9C, right panel). This type of analysis revealed that part of the
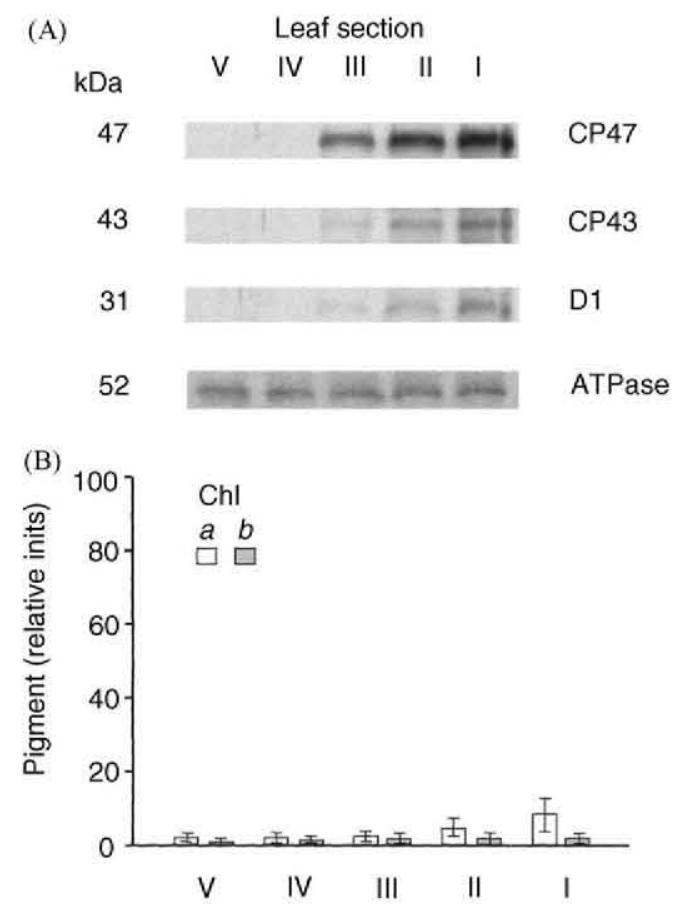

Fig. 10. CP47, CP43, and D1 protein, as well as $\mathrm{CF}_{0} / \mathrm{CF}_{1}-\mathrm{ATPase}$ subunit expression in relation to $\mathrm{Chl}$ levels during natural greening. Leaf protein extracts were prepared as described in Fig. 9. After immunoprecipitation using the indicated anti-CP47, anti-CP43, anti-D1 and anti-52 kDa $\mathrm{CF}_{0} / \mathrm{CF}_{1}$-ATPase subunit antisera, proteins and pigments were recovered from acetone extracts and quantified. (A) Western blot of CP47, CP43, D1 and $52 \mathrm{kDa} \mathrm{CF} / \mathrm{CF}_{1}$-ATPase subunit. (B) Quantification of $\mathrm{Chl} a$ and $\mathrm{Chl} b$ levels relative to the total amount of $\mathrm{Chl}$ in the various leaf tissues. Bars indicate standard deviations determined from five independent experiments. 
Chlide-complexed WSCP in leaf sectors I and II is present in terms of auto-fluorescing oligomers (Fig. 9C, upper band). In addition, also non-assembled, but non-fluorescing WSCP (Fig. 9C, lower band) was detectable in these leaf sectors and leaf sector III. In leaf sectors IV and V, WSCP levels remained below the limit of detection (data not shown, but see Fig. 8A)

Immunoprecipitations with heterologous antisera were performed to examine pigment binding to the $\mathrm{CP} 47, \mathrm{CP} 43$ and D1 proteins of photosystem II in the various leaf sectors. Fig. 10A demonstrates that the level of all three proteins continuously increased from sectors III to I, reflecting leaf development and proplastid-to-chloroplast differentiation. In the youngest parts of the plants (sectors IV and V) no immune signals were obtained (Fig. 10A). These leaf tissues expressed significant amounts of the $52 \mathrm{kDa}$ subunit of the $\mathrm{CF}_{0} / \mathrm{CF}_{1}$-ATPase, however (Fig. 10A). HPLC analyses on C30 RP material and differential solvent extractability with mixtures of hexane and acetone [30] demonstrated that the recovered pigments were present in their esterified forms (data not shown). Pigment identification and quantification by absorbance and fluorescence measurements at different wavelength unveiled binding of $\mathrm{Chl} a$, but not $\mathrm{Chl} b$, to the various PSII proteins (Fig. 10B).

\section{Discussion}

In the present study, we examined the regulated expression and function of the PORA and PORB of barley during seedling development. Two different experimental approaches were used to this end. In the first case, we grew barley plants in darkness and subsequently exposed the seedlings to a single, saturating $1 \mathrm{~ms}$ flash of white light. This experimental regime is referred to as "artificial greening" throughout the rest of the discussion. In the second case, we germinated barley seeds under quasi-native conditions underneath a layer of vermiculite in the presence of dim white light. This regime is referred to as "natural greening".

Consistent with previous findings [53,54], POR expression was found to be under developmental control. Highest POR protein levels were detected in the leaf tip containing mature etioplasts, whereas the middle leaf sector and the leaf base contained less POR protein (Fig. 1B). Superimposed on this developmental effect were differences in the actual PORA and PORB protein levels in the various leaf sections. PORA accumulated in the differentiated plastids present in sector I, II and III of the leaf, but not in proplastids found in the leaf base (Fig. 1B). However, in these less differentiated tissues, substantial amounts of the cytosolic PORA precursor, pPORA, were found. Despite the presence of Pchlide-628/632 (Fig. 2), these PORA precursor molecules were obviously not imported into the plastids and processed to mature size (Fig. 1B). An explanation for this finding could be that different pools of Pchlide were present in barley plastids and that Pchlide $a$ accumulating in proplastids (Fig. 3) was insufficient to trigger pPORA import. Consistent with this hypothesis is previous work showing that PORA binds Pchlide $b$ with 10-fold higher affinity than Pchlide $a$ [26]. The lack of Pchlide $b$ in the leaf base would thus be limiting for pPORA import. Alternatively, the import machinery through which the pPORA is imported $[55,56]$, may be under developmental control and thus may not be existent in a functional state in proplastids. Dahlin and Cline [45] observed that protein import is determined by developmental age of the plant.

In contrast to PORA, similar amounts of PORB accumulated across the barley leaf gradient (Fig. 1B). As shown previously, PORB is expressed in etiolated, illuminated and light-adapted plants [24], containing etioplasts, etiochloroplasts and mature chloroplasts, respectively. Import of the cytosolic PORB precursor (pPORB) does not depend on Pchlide [29,50,57-61] and occurs via the Toc machinery $[55,60]$

\subsection{Size modulation of LHPP}

PORA and PORB structurally interact with each other, as shown in this (Figs. 5 and 8) and previous work [25-27,62]. In addition to PORA and PORB and their cognate pigment substrates, the resolved supra-complex contains galacto- and sulfolipids that shift the absorption maximum of the reconstituted complex from 630 to $650 \mathrm{~nm}$ [25-27]. The resulting higher molecular mass complex displays UV, blue and red light-induced auto-fluorescence indicative of the presence of Pchlide-650/657. This correlative evidence suggests that the resolved supra-complex obeys the criteria previously set for LHPP [25]. Indeed, POR protein and pigment stoichiometries shown in this and a recent paper [26] demonstrated that the supra-complex recovered from leaf sectors II and III of plants kept under artificial and natural greening conditions, respectively, consisted of $\sim 5$ PORA-Pchlide $b-\mathrm{NADPH}$ and $\sim 1$ PORB-Pchlide a-NADPH ternary complexes (Figs. 1 and 7 , as well as Table 2). In tissues prepared from the leaf tip of fully etiolated plants, even higher Pchlide $b$ to Pchlide $a$ levels and a ca. 8.5-fold excess of PORA relative to PORB were detected (Fig. 1 and Table 2). Previous work in which the leaf tips of etiolated plants had been disregarded for protein and pigment extraction [25-27] thus underestimated the actual POR and pigment levels.

Size modulation of LHPP may be due to POR protein phosphorylation and changes in the protein-lipid interface not executed in previous in vitro-reconstitution experiments. Wiktorsson et al. [63] and Kovacheva et al. [64] proposed that ADP/ATP and POR phosphorylation may affect the formation and dispersal, i.e. the size, of the prolamellar body and organization state of POR-Pchlide complexes in etiolated plants. Kóta et al. [65] put forth gross alterations in the secondary structure of membrane proteins; conformation, composition, and dynamics of lipid acyl chains; as well as protein pattern. The authors argued that formation of the prolamellar body and subsequent greening may be accompa- 
nied by major reorganization events concerning both membrane protein assemblies and the protein-lipid interface.

The size of LHPP recovered from leaf sector II of fully etiolated plants of approximately $660 \mathrm{kDa}$ (Fig. 5C) at first glance seems to match that of the Pchlide holochrome of bean reported previously [6]. It is not known whether two differentially expressed por genes are present in bean plants. In the closely related pea system only one por gene has been cloned thus far [66] the identity of which is at variance with the detection of two differentially expressed POR polypeptides bands on western blots ([67] and S. Reinbothe, unpublished results). In cucumber, only one por gene and protein were reported $[68,69]$. These differences suggest that LHPP complexes similar to those identified in this and previous work for barley [36], wheat and Arabidopsis thaliana [70] may not be present in other oxygenic photosynthesizers. On the other hand, less evolved organisms, such as the liverwort (Marchantia paleacea) [71] and the green alga Chlamydomonas reinhardtii [72], lack multiple, differentially regulated por gene families. Instead they contain a second, highly conserved light-independent system for making chlorophyll in the dark. Collectively, these differences amongst different phyla and taxa in the por gene complement implicate environmental adaptations to the selection pressures encountered during evolution [73].

\subsection{Light-induced dissociation of LHPP}

In etiolated barley plants, Pchlide-650/657 was converted to Chlide-684/690 upon flash light-illumination (Figs. 2 and 3 ). At the same time higher molecular mass complexes containing both PORA and PORB dissociated into their subunits (Fig. 5). We previously observed that Chlide a formed as a result of flash light-treatment co-fractionated with PORB, whereas Pchlide $b$ bound to PORA did not undergo light-dependent conversion to Chlide $b$ [26]. On the basis of these observations we reconfirmed that Pchlide $b$ is not photoactive in LHPP. Nielsen [1,2] has shown that regeneration of Pchlide-650/657 after a flash light-pulse requires a certain lag-phase. This could imply that PORB-bound Chlide a needs to be replaced by fresh Pchlide $a$. In vivo, Pchlide a may either be freshly synthesized from protoporphyrin IX via the $\mathrm{Mg}$ branch of the C5-pathway or could alternatively be formed from excess Pchlide $b$ by virtue of 7-formyl reductase present in the prolamellar body. According to previous and recent work, barley etioplasts contain 7 -formyl reductase activity which converts a wide range of $b$-type porphyrins and chlorins to their a-type compounds $[27,74-77]$. A presumed intermediate in the conversion of Pchlide $b$ to Pchlide $a$ is 7-OH-Pchlide $a$ detected in this (Fig. 3, peak 1) and previous work [77].

\subsection{Greening under natural conditions involves WSCPS}

Under natural greening conditions, Pchlide-650/657 has also been identified (Fig. 6B; see also Ref. [78]). We ob- served that leaf tissues that contain Pchlide-650/657 also expressed higher molecular mass POR-pigment complexes containing the PORA and PORB (compare Figs. 6B and 8). The amount of both Pchlide-650/657 and higher molecular mass POR-pigment complexes was highest in leaf sector III, but lower in the adjacent leaf sector II. In leaf sector II, an additional fluorescence peak appeared, emitting at $672 \mathrm{~nm}$. In the leaf tip (sector I), little Pchlide-650/657 was present, and the emission maximum of this Pchlide species was slightly blue-shifted to $\sim 652 \mathrm{~nm}$. At the same time, a major fluorescence peak was detectable in the leaf tip that displayed an emission maximum at $684 \mathrm{~nm}$. According to previous work, the appearance of this peak may be due to the presence of free Chlide a, Chl a-complexed PSII reaction centers [34] or Chl-complexed WSCPs [41]. The accumulation of auto-fluorescing WSCP oligomers in the stroma of barley plastids recovered from leaf sectors I and II (Fig. 8 ) and of reaction center proteins and core antenna polypeptides, such as D1, CP47 and CP43 (Fig. 10), is compatible with these different views.

\subsection{A second route of chlorophyll synthesis in illuminated plants?}

The identity of the fluorescence peak emitting at $672 \mathrm{~nm}$ in leaf sectors II and III is unknown. These leaf sectors contained both Pchlide-628/632 and Pchlide-650/657. Interestingly, we observed PORB dimers under non-reducing electrophoresis conditions (Fig. 8). Both barley PORB and pea POR expressed as a maltose-binding protein also have been shown to form dimers and to display pigment fluorescence at $672 \mathrm{~nm}[79,80]$. Also in wheat, POR dimers have been identified by chemical cross-linking [81]. In a photomorphogenetic mutant of Arabidopsis designated det340/cop1, which does not express detectable PORA protein levels and contains drastically reduced prolamellar bodies, the same pigment species has been identified [34]. Lebedev et al. [34] proposed that $\mathrm{Chl}$ synthesis in det340/copl mutant plants may occur via a route not involving Pchlide-650/657 that is driven by PORB. Because Chl a accumulation was only observed under very low light intensities, Lebedev et al. [34] concluded that PORA's function might be to confer photoprotection onto the PORB. Work of Sperling et al. [82] confirmed such a view and demonstrated that PORA overexpression gave rise to a greater seedling survival rate after depletion of endogenous PORA by growth in far red light, which leads to a shut-down of PorA gene expression [83], than observed in the non-transformed wild-type. Remarkably, PORB overexpression also rescued the PORA deficiency, suggesting that there might be an overlap between PORA and PORB function in Arabidopsis. However, it is not yet clear how the recently discovered PORC [84-86] influenced data analysis and what role this third POR protein may play during $\mathrm{Chl}$ biosynthesis.

In summary, the results shown in this study and in previous work strengthen the view that PORA and PORB of barley 
accomplish unique functions in etiolated plants as part of a higher molecular mass light-harvesting complex. It remains to be tested whether there is a PORC in barley that may interact with PORB in light-adapted plants.

\section{Acknowledgements}

This work was inaugurated in the Department of Prof. Dr. E.W. Weiler at the Institute for Plant Physiology, Ruhr-Universitat Bochum, Bochum, Germany. We are grateful to $\mathrm{EW}$ for his stimulating interest and continuous support of the work. We thank Dr. Marcel Kuntz, CNRS, Grenoble, France, for expert help with HPLC and Dr. Hiroyuki Satoh, Department of Biomolecular Science, Toho University, Japan, for a gift of the anti-WSCP antiserum.

\section{References}

[1] O.F. Nielsen, Photoconversion and regeneration of active protochlorophyll(ide) in mutants defective in the regulation of chlorophyll synthesis, Arch. Biochem. Biophys. 160 (1974) 430-439.

[2] O.F. Nielsen, Macromolecular physiology of plastids. XIII. The effect of photoinactive protochlorophyllide on the function of protochlorophyllide holochrome, Biochem. Physiol. Pflanz. 167 (1975) 195-206.

[3] W.T. Griffiths, Characterization of the terminal stage of chlorophyll(ide) synthesis in etioplast membrane preparations, Biochem. J. 152 (1975) 623-635.

[4] W.T. Griffiths, Reconstitution of chlorophyll formation by isolated etioplast membranes, Biochem. J. 174 (1978) 681-692.

[5] K. Apel, H.-J. Santel, T.E. Redlinger, H. Falk, The protochlorophyllide holochrome of barley. Isolation and characterization of the NADPH:protochlorophyllide oxidoreductase, Eur. J. Biochem. 111 (1980) 251-258.

[6] N.K. Boardman, Studies on a protochlorophyll-protein complex. I. Purification and molecular weight determination, Biochem. Biophys. Acta 62 (1962) 63-79.

[7] N. Lebedev, M.P. Timko, Protochlorophyllide photoreduction, Photosynth. Res. 58 (1998) 5-23.

[8] C. Sundqvist, C. Dahlin, With chlorophyll from prolamellar bodies to light-harvesting complexes, Physiol. Plant. 100 (1997) 748-759.

[9] D. Granick, M. Gassman, Rapid regeneration of protochlorophyllide 650 , Plant Physiol. 45 (1970) 201-205.

[10] A.A. Kahn, N.K. Boardman, S.W. Thorn, Energy transfer between protochlorophyllide molecules: evidence for multiple chromophores in the photoactive protochlorophyllide-protein complex in vivo and in vitro, J. Mol. Biol. 48 (1970) 85-101.

[11] C. Sundqvist, The conversion of protochlorophyllide 636 to protochlorophyllide 650 in leaves treated with $\sigma$-aminolevulinic acid in continuous light and in flashlight, Physiol. Plant. 2 (1970) 147-156.

[12] E. Dujardin, C. Sironval, The mechanism of photoreduction of protochlorophyll (ide), in: G. Argyroudi-Akoyunoglou, J. Argyroudi-Akoyunoglou (Eds.), Chloroplast Development, Elsevier/North-Holland, Amsterdam, 1978. pp. 83-98.

[13] A. Kahn, Developmental physiology of bean leaf plastids. Tube transformation and protochlorphyll(ide) photoconversion by a flash irradiation, Plant Physiol. 43 (1968) 1781-1785.

[14] J.H.C. Smith, A. Benitez, The effect of temperature on the conversion of protochlorophyll to chlorophyll a in etiolated barley leaves, Plant Physiol. 29 (1954) 135-143.
[15] P. Mathis, K. Sauer, Circular dichroism studies on the structure and the photochemistry of protochlorophyllide and chlorophyllide holochrome, Biochim. Biophys. Acta 267 (1972) 498-511.

[16] G.D. Vaughan, K. Sauer, Energy transfer from protochlorophyllide to chlorophyllide during photoconversion of etiolated bean holochrome, Biochim. Biophys. Acta 347 (1974) 383-394.

[17] N.V. Ignatov, F.F. Litvin, Energy migration in a pigmented protochlorophyllide complex, Biofizika 26 (1981) 664-668.

[18] L.I. Fradkin, I.N. Domanskaya, M.S. Radyuk, V.P. Domanskii, V.M. Kolyago, Effect of benzyladenine and irradiation on energy transfer from precursor to chlorophyll in greening barley leaves, Photosynthetica 29 (1993) 227-234.

[19] R. Meskauskiene, M. Nater, D. Goslings, F. Kessler, R. op den Camp, K. Apel, FLU: a negative regulator of chlorophyll biosynthesis in Arabidopsis thaliana, Proc. Natl. Acad. Sci. U.S.A. 98 (2001) 12826-12831

[20] R. Meskauskiene, K. Apel, Interaction of FLU, a negative regulator of tetrapyrrole biosynthesis, with the glutamyl-tRNA reductase requires the tetratricopeptide repeat domain of FLU, FEBS Lett. 532 (2002) $27-30$.

[21] S. Reinbothe, C. Reinbothe, N. Lebedev, K. Apel, PORA and PORB, two light-dependent protochlorophyllide-reducing enzymes of angiosperm chlorophyll biosynthesis, Plant Cell 8 (1996) 763-769.

[22] S. Reinbothe, C. Reinbothe, The regulation of enzymes involved in chlorophyll biosynthesis, Eur. J. Biochem. 237 (1996) 323-343.

[23] R. op den Camp, D. Przybyla, C. Ochsenbein, C. Laloi, C. Kim, A. Danon, D. Wagner, E. Hideg, C. Gobel, I. Feussner, M. Nater, K. Apel, Rapid induction of distinct stress responses after the release of singlet oxygen in Arabidopsis, Plant Cell 15 (2003) 2320-2332.

[24] H. Holtorf, S. Reinbothe, C. Reinbothe, B. Bereza, K. Apel, Two routes of chlorophyllide synthesis that are differentially regulated by light in barley, Proc. Natl. Acad. Sci. U.S.A. 92 (1995) 32543258.

[25] C. Reinbothe, N. Lebedev, S. Reinbothe, A protochlorophyllide light-harvesting complex involved in de-etiolation of higher plants, Nature 397 (1999) 80-84.

[26] C. Reinbothe, F. Buhr, S. Pollmann, S. Reinbothe, In vitro-reconstitution of LHPP with protochlorophyllides $a$ and $b, \mathrm{~J}$. Biol. Chem. 278 (2003) 800-806.

[27] S. Reinbothe, S. Pollmann, C. Reinbothe, In-situ-conversion of protochlorophyllide $b$ to protochlorophyllide $a$ in barley. Evidence for a novel role of 7 -formyl reductase in the prolamellar body of etioplasts, J. Biol. Chem. 278 (2003) 807-815

[28] H. Smith, Light quality photoperception and plant strategy, Annu. Rev. Plant Physiol. 33 (1982) 481-518.

[29] S. Reinbothe, S. Runge, C. Reinbothe, B. van Cleve, K. Apel, Substrate-dependent transport of the NADPH:protochlorophyllide oxidoreductase into isolated plastids, Plant Cell 7 (1995) 161-172.

[30] M. Helfrich, S. Schoch, U. Lempert, U. Cmiel, W. Riidiger, Chlorophyll synthetase cannot synthesize chlorophyll a', Eur. J. Biochem. 219 (1994) 267-275.

[31] V. Scheumann, H. Klement, M. Helfrich, U. Oster, S. Schoch, W. Riidiger, Protochlorophyllide $b$ does not occur in barley etioplasts, FEBS Lett. 445 (1999) 445-448.

[32] P.D. Fraser, E.M.S. Pinto, D.E. Holloway, P.M. Bramley, Application of high-performance liquid chromatography with photodiode array detection to the metabolite profiling of plant isoprenoids, Plant J. 24 (2000) 551-555.

[33] U. Oster, R. Tanaka, A. Tanaka, W. Riidiger, Cloning and functional expression of the gene encoding the key enzyme for chlorophyll $b$ biosynthesis (CAO) from Arabidopsis thaliana, Plant J. 21 (2000) 305-310.

[34] N. Lebedev, B. van Cleve, G.A. Armstrong, K. Apel, Chlorophyll synthesis in a deetiolated (det340) mutant of Arabidopsis without NADPH-protochlorophyllide (PChlide) oxidoreductase (POR) A and photoactive PChlide-F655, Plant Cell 7 (1995) 2081-2090.

[35] U.K. Laemmli, Cleavage of structural proteins during the assembly of the head of bacteriophage T4, Nature 227 (1970) 680-685. 
[36] K.-D. Scharf, L. Nover, Heat-shock-induced alterations of ribosomal protein phosphorylation in plant cell cultures, Cell 30 (1982) 427 437.

[37] R. Krauspe, S. Lerbs, B. Parthier, R. Wollgiehn, Light-induction of Euglena chloroplast aminoacyl-tRNA synthetase mRNAs, J. Plant Physiol. 130 (1987) 327-342.

[38] M. Towbin, T. Staehelin, J. Gordon, Electrophoretic transfer of proteins from polyacrylamide gels to nitrocellulose sheets; procedure and some applications, Proc. Natl. Acad. Sci. U.S.A. 76 (1979) $4350-4354$.

[39] J.-Y. Chang, Manual micro-sequence analysis of peptides and proteins using 4-N,N-dimethylaminoazobenzene 4 isothio-cyanate/ phenylisothiocyanate double coupling method, FEBS Lett. 93 (1983) $205-214$.

[40] J.-Y. Chang, D. Brauer, B. Wittmann-Liebold, Micro-sequence analysis of polypeptides using dimethylaminoazobenzene isothiocyanate, Meth. Enzymol. 91 (1978) 455-466.

[41] H. Satoh, K. Nakayama, M. Okada, Molecular cloning and functional expression of a water-soluble chlorophyll protein, a putative carrier of chlorophyll molecules in cauliflower, J. Biol. Chem. 273 (1998) 30568-30575.

[42] M. Wiedmann, T. Kurzchalia, H. Bielka, T.A. Rapoport, Direct probing of the interaction between the signal sequence of nascent preprolactin and the signal recognition particle by specific crosslinking, J. Cell Biol. 104 (1987) 201-209.

[43] R.E. Kendrick, G.H. Kronenberg, Photomorphogenesis in Plants, Martinus Nijhoff, Dordrecht, 1994

[44] J.T.O. Kirk, R.A.E. Tilney-Basset, The Plastids: Their Chemistry, Structure, Growth and Inheritance, Elsevier/North-Holland Biomedical Press, Amsterdam/New York, 1978.

[45] C. Dahlin, K. Cline, Developmental regulation of the plastid protein import apparatus, Plant Cell 3 (1991) 1131-1140.

[46] S. Reinbothe, C. Reinbothe, D. Neumann, K. Apel, A plastid enzyme arrested in the step of precursor translocation in vivo, Proc. Natl. Acad. Sci. U.S.A. 93 (1996) 12026-12030.

[47] D. von Wettstein, S. Gough, C.G. Kannangara, Chlorophyll biosynthesis, Plant Cell 7 (1995) 1039-1057.

[48] H.I. Virgin, A. Kahn, D. von Wettstein, The physiology of chlorophyll formation in relation to structural changes in chloroplasts, Photochem. Photobiol. 2 (1963) 83-91.

[49] K.W. Henningsen, Macromolecular physiology of plastids. IV. Changes in membrane structure associated with shifts in the absorption maxima of chlorophyllous pigments, J. Cell Sci. 7 (1970) $587-621$.

[50] S. Reinbothe, C. Reinbothe, H. Holtorf, K. Apel, Two NADPH:protochlorophyllide oxidoreductases in barley: evidence for the selective disappearance of PORA during the light-induced greening of etiolated seedlings, Plant Cell 7 (1995) 1933-1940.

[51] C. Reinbothe, K. Apel, S. Reinbothe, A light-induced protease from barley plastids degrades NADPH:protochlorophyllide oxidoreductase complexed with chlorophyllide, Mol. Cell. Biol. 15 (1995) 62066212.

[52] C. Reinbothe, H. Satoh, J.-P. Alcaraz, S. Reinbothe, A novel role of water-soluble chlorophyll proteins in transitory storage of chorophyllide, Plant Physiol. 134, 1355-1365.

[53] K. Dehesh, I. Hauser, K. Apel, K. Kloppstech, The distribution of NADPH-protochlorophyllide oxidoreductase in relation to chlorophyll accumulation along the barley leaf gradient, Planta 158 (1983) 134-139.

[54] H.J. Ougham, A.M. Thomas, B.J. Thomas, G.A. Frick, G.A. Armstrong, Both light-dependent protochlorophyllide oxidoreductase A and protochlorophyllide oxidoreductase $\mathrm{B}$ are down-regulated in the slender mutant of barley, J. Exp. Bot. 52 (2001) 1447-1454.

[55] S. Reinbothe, F. Quigley, J. Gray, A. Schemenewitz, C. Reinbothe, Identification of plastid envelope proteins required for the import of protochlorophyllide oxidoreductase (POR) A into the chloroplast of barley, Proc. Natl. Acad. Sci. U.S.A. 101 (2004) 2197-2202.
[56] S. Reinbothe, F. Quigley, A. Springer, A. Schemenewitz, C. Reinbothe, The outer plastid envelope protein Oep16: novel role as precursor translocase in import of protochlorophyllide oxidoreductase A, Proc. Natl. Acad. Sci. U.S.A. 101 (2004) 2203-2208.

[57] S. Reinbothe, C. Reinbothe, S. Runge, K. Apel, Enzymatic product formation impairs both the chloroplast receptor binding function as well as translocation competence of the NADPH:protochlorophyllide oxidoreductase, a nuclear-encoded plastid protein, J. Cell Biol. 129 (1995) 299-308.

[58] C. Reinbothe, N. Lebedev, K. Apel, S. Reinbothe, Regulation of chloroplast protein import through a protochlorophyllide-responsive transit peptide, Proc. Natl. Acad. Sci. U.S.A. 94 (1997) 8890-8894.

[59] C. Reinbothe, R. Mache, S. Reinbothe, A second, substrate-dependent site of protein import into chloroplasts, Proc. Natl. Acad. Sci. U.S.A. 97 (2000) 9795-9800.

[60] H. Aronsson, K. Sohrt, J. Soll, NADPH:protochlorophyllide oxidoreductase uses the general import route into chloroplasts, Biol. Chem. 381 (2000) 1263-1267.

[61] C. Dahlin, H. Aronsson, J. Almkvist, C. Sundqvist, Protochlorophyllide-independent import of two NADPH:Pchlide oxidoreductase proteins (PORA and PORB) from barley into isolated plastids, Physiol. Plant. 109 (2000) 298-303.

[62] C. Reinbothe, A. Lepinat, M. Deckers, E. Beck, S. Reinbothe, The extra loop distinguishing POR from the structurally related short-chain alcohol dehydrogenases is dispensable for pigment binding, but needed for the assembly of LHPP, J. Biol. Chem. 278 (2003) $816-822$.

[63] B. Wiktorsson, M. Ryberg, C. Sundqvist, Aggregation of NADPH-protochlorophyllide oxidoreductase-pigment complexes is favoured by protein phosphorylation, Plant Physiol. Biochem. 34 (1996) 23-34.

[64] S. Kovacheva, M. Ryberg, C. Sundqvist, ADP/ATP and protein phosphorylation dependence of phototransformable protochlorophyllide in isolated etioplast membranes, Photosynth. Res. 64 (2000) 127 136.

[65] Z. Kota, L.J. Horvath, M. Droppa, G. Horvath, T. Farkas, T. Pali, Protein assembly and heat stability in developing thylakoid membranes during greening, Proc. Natl. Acad. Sci. U.S.A. 99 (2002) 12149-12154.

[66] A.J. Spano, Z. He, H. Michel, D.F. Hunt, M.P. Timko, Molecular cloning, nuclear gene structure, and developmental expression of NADPH-protochlorophyllide oxidoreductase in pea (Pisum sativum L.), Plant Mol. Biol. 18 (1992) 967-972.

[67] Z.-H. He, J. Li, G. Sundqvist, M.P. Timko, Leaf developmental age control of expression of genes encoding enzymes of chlorophyll and heme biosynthesis in pea (Pisum sativum L.), Plant Physiol. 106 (1994) 537-546.

[68] N. Fusada, T. Masuda, H. Kuroda, T. Shiraishi, H. Shimada, H Ohta, K.-I. Takamiya, NADPH-protochlorophyllide oxidoreductase in cucumber is encoded by a single gene and its expression is transcriptionally enhanced by illumination, Photosynth. Res. 64 (2000) $147-154$.

[69] H. Kuroda, T. Masuda, H. Ohta, Y. Shioi, K. Takamiya, Light-enhanced gene expression of NADPH-protochlorophyllide oxidoreductase in cucumber, Biochem. Biophys. Res. Commun. 210 (1995) 310-316.

[70] S. Reinbothe, C. Reinbothe, Light-harvesting protochlorophyllide binding protein complex (LHPP) is developmentally expressed in angiosperms, in: K. Schnarrenberger, B. Wittmann-Liebold (Eds.), Proceedings of the 12th International Congress on Genes, Gene Families and Isozymes, Monduzzi Editore, Bologna, Italy, 2003, pp. 235-239.

[71] S. Takio, N. Nakao, T. Suzuki, K. Tanaka, I. Yamamoto, T. Satoh, Light-dependent expression of protochlorophyllide oxidoreductase gene in the liverwort, Marchantia paleacea var. diptera, Plant Cell Physiol. 39 (1998) 665-669. 
[72] J.M. Le, M.P. Timko, The pc-1 phenotype of Chlamydomonas rein hardtii results from a deletion mutation in the nuclear gene for NADPH:protochlorophyllide oxidoreductase, Plant Mol. Biol. 30 (1996) 15-37.

[73] G. Frick, Q. Su, K. Apel, G.A. Armstrong, An Arabidopsis porB-porC double mutant lacking light-dependent NADPH: protochlorophyllide oxidoreductases $\mathrm{B}$ and $\mathrm{C}$ is highly chlorophylldeficient and developmentally arrested, Plant J. 25 (2003) 141-153.

[74] H. Ito, Y. Tanaka, H. Tsuji, A. Tanaka, Conversion of chlorophyll $b$ to chlorophyll $a$ by isolated cucumber etioplasts, Arch. Biochem. Biophys. 306 (1993) 148-151.

[75] H. Ito, S. Takaichi, H. Tsuji, A. Tanaka, Properties of synthesis of chlorophyll a from chlorophyll $b$ in cucumber etioplasts, J. Biol. Chem. 269 (1994) 22034-22038.

[76] H. Ito, T. Ohtsuka, A. Tanaka, Conversion of chlorophyll $b$ to chlorophyll a via 7-hydroxymethyl chlorophyll, J. Biol. Chem. 271 (1996) 1475-1479.

[77] V. Scheumann, H. Ito, A. Tanaka, S. Schoch, W. Riidiger, Substrate specificity of chlorophyll(ide) $b$ reductase in etioplasts of barley, Eur. J. Biochem. 242 (1996) 163-170.

[78] F. Franck, K. Strzalka, Detection of the photoactive protochlorophyllide complex in the light during the greening of barley, FEBS Lett. 309 (1992) 73-77.

[79] G.E.M. Martin, M.P. Timko, H.M. Wilks, Purification and kinetic analysis of pea NADPH-protochlorophyllide oxidoreductase expressed as a fusion with maltose-binding protein in Escherichia coli, Biochem. J. 325 (1997) 139-143.
[80] N. Lebedev, M.P. Timko, Protochlorophyllide oxidoreductase B-catalyzed protochlorophyllide photoreduction in vitro: Insight into the mechanism of chlorophyll formation in light-adapted plants, Proc. Natl. Acad. Sci. U.S.A. 96 (1999) 9954-9959.

[81] B. Wiktorsson, S. Engdahl, L.B. Zhong, B. Boddi, M. Ryberg, C. Sundqvist, The effect of cross-linking of the subunits of NADPH-protochlorophyllide oxidoreductase on the aggregation state of protochlorophyllide, Photosynthetica 29 (1993) 205-218.

[82] U. Sperling, B. van Cleve, G. Frick, K. Apel, G.A. Armstrong, Overexpression of light-dependent PORA and PORB in plants depleted of endogenous POR by far-red light enhances seedling survival in white light and protects against photooxidative damage, Plant J. 12 (1997) 649-658.

[83] S. Runge, U. Sperling, G. Frick, K. Apel, G.A. Armstrong, Distinct roles for NADPH:protochlorophyllide oxidoreductases (POR) A and $\mathrm{B}$ during greening in higher plants, Plant J. 9 (1996) 513-523.

[84] N. Oosawa, T. Masuda, K. Awai, N. Fusada, H. Shimada, H. Ohta, K. Takamya, Identification and light-induced expression of a novel NADPH-protochlorophyllide oxidoreductase isoform in Arabidopsis thaliana, FEBS Lett. 474 (2000) 133-136.

[85] G.K. Pattanayak, B. Tripathy, Catalytic function of a novel protein protochlorophyllide oxidoreductase $\mathrm{C}$ of Arabidospsis thaliana, Biochim. Biophys. Res. Commun. 291 (2002) 921-924.

[86] X. Su, G. Frick, G. Armstrong, K. Apel, PORC of Arabidopsis thaliana: a third light- and NADPH-dependent protochlorophyllide oxidoreductase that is differentially regulated by light, Plant Mol. Biol. 47 (2002) 805-813. 